\title{
Reseña de Wobeser, Gisela von, Apariciones de seres celestiales y demoniacos en la Nueva España, México, UNAM, 2016, 139 pp. ISBN 978-607-02-8324-6
}

\author{
Jean Christian Egoávil \\ Universidad del Pacífico \\ PERÚ \\ jc.egoavilr@up.edu.pe
}

[Hipogrifo, (issn: 2328-1308), 6.1, 2018, pp. 721-724]

Recibido: 20-11-2017 / Aceptado: 22-01-2018

DOI: http://dx.doi.org/10.13035/H.2018.06.01.49

Toda época histórica se contextualiza en una extensión geográfica determinada y en una atmósfera social y política concreta. Los personajes que se incluyen en esta exhiben una variopinta heterogeneidad de roles como reyes, militares, líderes religiosos, hombres de ciencia y de artes, campesinos, comerciantes y obreros. Ellos transfirieron a la posteridad un conjunto de testimonios que nos permiten reconstruir los pormenores de sus vidas. Pero una revisión más profunda de estos testimonios nos revela dimensiones subyacentes que normalmente no se perciben. Una de estas dimensiones es la espiritual, cuya manifestación religiosa es resguardada por todos los pueblos como patrimonio de su fe espiritual.

La historia del virreinato de la Nueva España, cuya capital fue la ciudad de México, corrobora la importante función que la religión cumplió en la vida cotidiana de sus habitantes. Gran parte del imaginario novohispano tuvo una orientación religiosa. Las principales manifestaciones religiosas giraban en torno a los cultos, ritos, devociones y conmemoraciones establecidas por el santoral católico. Como parte de estas exteriorizaciones, la tradición aparicionista destaca por su peculiaridad, pues estaba reservada solo para los visionarios.

El libro de la doctora Gisela von Wobeser tiene una importancia capital, pues analiza los testimonios con una exhaustiva metodología histórica y hermenéutica con el objetivo de «entender el papel que representaron estos fenómenos religiosos en el imaginario virreinal y analizar sus implicaciones sociales y económicas» (p. 13). Su trabajo profundiza en las capas del imaginario religioso y social 
novohispánico para mostrar las íntimas correlaciones que se establecieron entre las manifestaciones religiosas y la vida social, política y económica conforme a lo que muchos estudiosos denominan teopolítica real hispana. El desarrollo argumentativo de la doctora von Wobeser se divide en cinco capítulos ordenados temáticamente: el primero explica el contexto histórico, literario y doctrinal de las apariciones cuyos principales elementos provienen de la herencia de la religiosidad medieval. El segundo, tercero y cuarto analizan las apariciones celestiales, demoníacas y anímicas respectivamente. El quinto estudia el caso paradigmático de Catarina de San Juan. A continuación desglosaremos los ejes temáticos del estudio de von Wobeser.

La exposición del capítulo primero se explica por medio de tres líneas interpretativas. La primera es la línea histórica, cuyo análisis nos sitúa en el contexto del virreinato mexicano, donde «los visionarios compartieron la preocupación religiosa central de los novohispanos de salvar su alma, así como la idea de que la vida terrenal era transitoria y que la verdadera realización de las personas se lograba en la eternidad» (p. 17). Asimismo, identifica a los protagonistas de dichas experiencias y a los espacios concretos en los que se desarrolla la acción. En cuanto a los primeros, sobresalen los religiosos, las beatas y los ermitaños, cuya predisposición espiritual les facilitaba la posibilidad de ser testigos de apariciones y visiones. Sin embargo, la Inquisición los vigilaba constantemente, pues «aunque la mayoría de los visionarios perseguían fines piadosos, hubo algunos que utilizaron sus dotes, reales o fingidos, como un medio para ganar reconocimiento social y perseguir beneficios materiales» (p. 17). En cuanto a los lugares, la autora menciona los conventos, donde «las apariciones y visiones de seres del más allá generalmente se dieron en la intimidad de la celda, sin presencia de terceros» (p. 16), las ermitas y las casas de las beatas.

En segundo lugar, por medio de la línea literaria von Wobeser analiza dos tipos de fuentes: la fuente directa y la indirecta. La primera está compuesta por cartas, diarios, crónicas conventuales, procesos inquisitoriales y relatos de los confesores. La segunda la componen las hagiografías o Vidas de santos. Es importante señalar que muchas de las hagiografías alimentaron el imaginario religioso y «era frecuente que los visionarios recrearan escenas de apariciones que habían escuchado o leído en las hagiografías y las enriquecieran con sus propias experiencias» (p. 19).

En tercer lugar, mediante la línea doctrinal, nuestra autora analiza el modo en que los testimonios eran evaluados con el objetivo de asegurar su veracidad o falsedad. La primera instancia de este proceso era la del confesor, pues «eran los confesores quienes debían verificar la autenticidad de las visiones y los místicos tenían la obligación de someterse con obediencia y humildad a sus veredictos» (p. 33). La segunda instancia era el Santo Oficio, quien dictaminaba el veredicto final del testimonio, «pero incluso para los inquisidores llegaba a ser complicado calificar la autenticidad de supuestos hechos sobrenaturales porque, en la mayoría de los casos, el contenido de las visiones consideradas auténticas y el de las juzgadas falsas era similar. Por esta razón, los inquisidores, para dictar las sentencias, solían basarse más en el estilo de vida de los visionarios que en las visiones mismas» (p. 33). 
Los capítulos segundo, tercero y cuarto corresponden al análisis de los testimonios de las apariciones clasificadas en: 1) apariciones de seres celestiales (segundo capítulo), 2) apariciones del demonio y de las huestes diabólicas (tercer capítulo) y 3) apariciones de ánimas del purgatorio (cuarto capítulo). Las apariciones celestiales se ordenan en «apariciones de Jesucristo», «apariciones de la Virgen María», «apariciones de ángeles»y «apariciones de almas bienaventuradas». Con un criterio similar organiza el análisis sobre las apariciones del Demonio («El Demonio, emperador del mal», «tentaciones y acosos diabólicos», «Aproximaciones eróticas», «posesiones y pactos diabólicos» y las «armas contra el Demonio») y las apariciones de ánimas del purgatorio («las ánimas del purgatorio», «el sufrimiento de las ánimas y su liberación mediante sufragios e indulgencias», «aparición de ánimas para solicitar sufragios» y los «actos violentos cometidos por ánimas del purgatorio»).

El análisis de los testimonios toma en cuenta tres aspectos a lo largo de estos capítulos. En primer lugar, aparece el aspecto psicológico de las personas quienes se esforzaban constantemente en imitar la vida de santos de modo que «las historias de apariciones reflejan el mundo interior de los visionarios y manifiestan sus emociones: amor, temor, odio, esperanza, miedo, ternura, piedad y compasión, entre otras» (p. 35). Estos sentimientos en una sociedad rígida se sublimaban muchas veces en visiones con implicancias sexuales, como el caso de las apariciones de Jesucristo, donde «las monjas y las beatas, que de acuerdo con el imaginario de la época se creían sus esposas, orientaban hacia él sus necesidades afectivas y sexuales. Muchas de las visiones y apariciones que experimentaron reflejan sentimientos de amor y denotan un erotismo sublimado» (p. 38).

En segundo lugar, se encuentra el aspecto intencional de las apariciones en tanto que cada una de estas tiene una intención o finalidad. Los seres celestiales exhortaban y bendecían, mientras que los demonios no solo tentaban, sino también agredían, como afirma von Wobeser: «[el Demonio] era un ser muy temido, no solo por las tentaciones a las que exponía a las personas y por su capacidad de actuar sobre los fenómenos naturales y ocasionar el mal en la tierra, sino porque se creía que llegaba a agredir en forma física a sus víctimas» (p. 56). E incluso podía atormentar y molestar la vida diaria tanto que «durante las celebraciones religiosas se intensificaban los acosos demoniacos» (p. 61), ya que «existía la idea de que el Demonio tentaba especialmente a las personas que eran más próximas a Dios, entre ellas las monjas, los clérigos, los ascetas, los ermitaños y las beatas» (p. 58).

Las tentaciones eróticas fueron constantes en los religiosos, como fue el caso del carmelita Fray Buenaventura, a quien «le encargaron el cuidado de la portería de su convento, lo que aprovechó el Demonio para enviarle a una mujer lasciva, la cual vino a provocarlo la primera noche» (p. 63). Del mismo modo, «los pactos solían firmarse con sangre, como fue el caso de un joven que quería poseer a toda costa a una muchacha sin lograrlo. Desesperado, una noche se fue a una callejuela agosta, situada junto al convento de San Francisco, y una vez que se cercioró de que nadie lo miraba, llamó al Demonio para que lo ayudara» (p. 64).

La visión de las almas del purgatorio tenía como finalidad el pedido de indulgencias y sufragios. Es decir, «desde el punto de vista teológico, la aparición de las al- 
mas purgantes, más conocidas como ánimas, se basaba en la creencia de que los fieles de la tierra podían ayudar a que éstas lograran su liberación mediante sufragios, y que Dios permitía que algunas de ellas vinieran a la tierra para buscar a sus allegados y pedirles su apoyo. Los sufragios consistían en misas dedicadas a las almas, rezos, penitencias o donaciones para instituciones eclesiásticas o de beneficencia» (p. 71). Además, es importante destacar el rol que desempeñó la retórica como instrumento para el pedido; puesto que, «tuvo hondas repercusiones sociales y económicas, tanto para las personas que creían alcanzar el cielo mediante indulgencias y sufragios como para las instituciones que resultaron beneficiadas con estos últimos» (p. 86).

La trascendencia del aspecto teopolítico de las apariciones es acentuada por la profesora von Wobeser, «ya que la presencia de seres celestiales en la tierra se consideraba un favor especial que Dios hacía a sus elegidos» (p. 12).

En el último capítulo, nuestra autora analiza el caso de la visionaria de origen filipino llevada a México: Catarina de San Juan. Las hagiografías escritas por los jesuitas detallan las experiencias de esta religiosa como auténticas y, a su vez, muestran el rico mundo interior y la extraordinaria «capacidad persuasiva para transmitir sus experiencias sobrenaturales a sus contemporáneos, especialmente a sus confesores, quienes se convirtieron en sus hagiógrafos» (p. 98). De modo que «a su muerte, Catarina fue objeto de unas exequias dignas de una persona de la más alta jerarquía social, organizadas por los jesuitas con el apoyo del cabildo catedralicio, de su benefactor Hipólito del Castillo y Altra y de diversos sectores de la sociedad poblana» (p. 94).

Catarina se regocijó como esposa mística de Jesucristo y disfrutó de la amistad de la Virgen María, «a quien veneraba en distintas advocaciones, y muy especialmente como Nuestra Señora de la Congregación, también llamada Pópulo, la patrona de la Compañía de Jesús» (p. 106). Asimismo, fue víctima de las tentaciones diabólicas y libró intensos combates espirituales con los demonios, donde siempre salía victoriosa. Aunque la postulación de su canonización haya sido impedida por la Inquisición, asegura von Wobeser que «la obra sobre Catarina de San Juan ejemplifica el auge que las apariciones de seres del más allá tuvieron en el siglo XVII y el importante papel que desempeñaron en la sociedad de su tiempo» (p. 126).

Finalmente, la base documental de este estudio es amplia, variada y escogida con un riguroso criterio que corresponde con el análisis de los casos presentados. Cuenta con una extensa cantidad de fuentes primarias consultadas como hagiografías, crónicas conventuales, documentos eclesiásticos oficiales y tratados teológicos. A estas fuentes primarias se suman estudios críticos actuales y ensayos especializados sobre apariciones místicas en la Nueva España. La bibliografía consultada por la profesora von Wobeser permite a los futuros investigadores tener una fuente ordenada de textos con la que puedan guiar sus trabajos. Por último, este libro constituye un extraordinario aporte para el estudio y la comprensión de nuestra riquísima herencia cultural. 